\title{
IMPACTOS SOCIAIS DA AGROINDÚSTRIA CANAVIEIRA NA COMUNIDADE DE PESCADORES DE BAÍA FORMOSA (RN) SOCIAL IMPACTS OF SUGAR-CANE
AGROINDUSTRY IN THE FISHING
COMMUNITY OF BAÍA FORMOSA (RN)
}

\author{
Julienne Louise dos Santos Govindin \\ jugovindin@gmail.com \\ Antropóloga e Mestra em Desenvolvimento e Meio Ambiente pela Universidade Federal do Rio Grande do \\ Norte (UFRN). \\ Francisca de Souza Miller \\ fransmiller56@yahoo.com.br \\ Professora do Programa de Pós-Graduação em Antropologia Social da Universidade Federal do Rio Grande \\ do Norte (UFRN).
}

\section{RESUMO}

A agroindústria canavieira é um dos fatores que causam fortes danos na Mata Atlântica do Nordeste brasileiro, sobretudo através do desmatamento para introdução dos canaviais e instalação do aparato industrial. Além dos danos na biodiversidade, há também danos sociais que afetam as comunidades que sobrevivem direta ou indiretamente do bioma da Mata Atlântica. Esse artigo possui como objetivo identificar as principais mudanças sociais na comunidade de pescadores de Baía Formosa/RN, geradas a partir da instalação de uma usina sucroalcooleira e a criação de uma unidade de conservação, e analisar os impactos sociais verificando a natureza destes negativos ou/e positivos, diretos ou indiretos. Para tanto, fundamentou-se numa abordagem qualitativa e perspectiva diacrônica, e fez uso da pesquisa bibliográfica e da história oral em conjunto com algumas técnicas e instrumentos de pesquisa como a observação direta, entrevista, registros de imagens e gravações. Identificaram-se impactos diretos negativos: perda do acesso às áreas de plantio, restrição de acesso aos recursos naturais e desmatamento. Positivos: visibilidade do município e preservação ambiental. Positivo e negativo: geração de empregos. Impactos indiretos: declínio da prática social da agricultura; perda do patrimônio cultural local; alteração na valorização que se atribui ao conhecimento ligado a mata; perda do saber-fazer da arte da carpintaria naval; empregos na safra da cana de açúcar; abandono de prática social da pesca; empregos atraídos pelo ecoturismo na mata; restrição de acesso para se trabalhar como guia; infraestrutura; atração do turismo; alteração dos recursos naturais; perda do significado mítico ou sagrado agregado à área perdida; contribui barrando o avanço da cana;

Palavras-chave: Impactos sociais. Comunidade pesqueira. Agroindústria canavieira.

\section{ABSTRACT}

The sugar-cane agroindustry is one of the factors that cause heavy damage to the Atlantic Forest of the Brazilian Northeast, especially by deforestation for the introduction of sugarcane fields and installation of industry structure. Besides the damages over biodiversity, 
there are critical social problems that affect the communities which survive using directly or indirectly the biome from the Atlantic Forest. This article aims to identify the main social changes in the fisher's community of Baía Formosa/RN after the installation of a sugar-cane factory and the creation of a conservation unit, and analyze the social impacts checking their nature, either negative and/or positive, direct or indirect ones. For that reason, it was based on a qualitative approach and diachronic perspective, and made use of literatures and oral history together with some technical and research tools such as direct observation, interview, records images and recordings. Negative direct impacts identified: loss of access to planting areas, restriction of access to natural resources and deforestation. Positive: exposure of the town and environmental preservation. Positive and negative: creation of jobs. Indirect impacts: decline of the social practice of agriculture; loss of local cultural heritage; value changes that are attributed to knowledge linked to forest; loss of know-how of the art of naval carpentry; jobs in the sugar cane harvest; abandonment of social practice of fishing; ecotourism attracted by jobs in the woods; restricting access to work as a guide; infrastructure; tourism attraction; alteration of natural resources; loss of mythic or sacred significance added to the lost area; contributes barring the advance of sugarcane.

Keywords: Social impacts. Fishing community. Sugarcane agroindustry.

\section{INTRODUÇÃO}

A colonização europeia no Brasil foi marcada pela exploração dos recursos naturais. Essa exploração foi mais intensa na Mata Atlântica, pois essa se encontrava ao longo do litoral, onde se instalaram os primeiros núcleos da colonização. A Mata Atlântica é uma das florestas tropicais mais ricas e diversas do mundo, abrigando mais de 21 mil espécies de plantas, anfíbios, aves, répteis e mamíferos. Estendia-se originalmente por aproximadamente $1.300 .000 \mathrm{Km}^{2}$ em 17 estados do território brasileiro. Hoje, os remanescentes de vegetação nativa estão reduzidos a cerca de $8 \%$ de sua cobertura original (INPE,2013). Historicamente no nordeste brasileiro, essa vegetação foi atingida principalmente pelo grande ciclo econômico da cana-de-açúcar. Andrade (1994) afirma que para desenvolver a cultura da cana-de-açúcar, os portugueses tiveram de se apropriar das terras indígenas, destruir as matas, construir engenhos de açúcar, escravizar indígenas e africanos e montar uma estrutura para a exportação do produto. $\mathrm{Na}$ contemporaneidade, um dos fatores que mais tem atingido a Mata Atlântica é a agroindústria, através da monocultura de cana de açúcar e usinas de beneficiamento de açúcar e álcool combustível. Segundo Diegues (2002), a monocultura em conjunto com a implantação das usinas sucroalcooleiras apresenta sérios problemas. A situação é ainda mais grave no Nordeste, onde essa cultura está atingindo os tabuleiros e se alastrando para os vales dos rios e estuários.

Os problemas ambientais oriundos da monocultura da cana-de-açúcar são inúmeros. Entre os principais podemos citar o desmatamento para introdução dos canaviais e instalação do aparato industrial e a poluição das águas, através do despejo de poluentes gerados pelas destilarias de álcool como o vinhoto nos rios e lagoas. Esses problemas foram agravados na década de 1970 com o surgimento do Proálcool (Política de Desenvolvimento da Produção de Álcool). Em 1975 inicia-se então uma aceleração na ocupação de áreas para implantação de destilarias por empresários com altos financiamentos do Governo. Segundo Andrade (1994), a expansão dos canaviais nos tabuleiros, com o Proálcool, agravou ainda mais os problemas sociais e ecológicos, desorganizando a frágil e pequena produção agrícola de uma área superpovoada e maximizando o problema da poluição dos cursos d'agua.

Em resposta aos danos ambientais, sobretudo a partir da década de 1970 começou-se a estabelecer instituições, mecanismos e legislações destinadas à conservação do chamado "mundo natural" (DIEGUES, 2000). A partir disto surgem no Brasil as unidades de conservação como pilares para a conser- 
vação da biodiversidade. A primeira unidade de conservação estabeleceu-se em 1934, o Parque Nacional do Itatiaia, localizado nos estados do Rio de Janeiro e de Minas Gerais e em 2000 se instituiu o sistema legal que definiu e regulamentou as áreas protegidas, em todos os níveis, o Sistema Nacional de Unidades de Conservação da Natureza (SNUC) (SCHIAVETTI; MAGRO; SANTOS, 2012).

Além dos danos a biodiversidade, há também sérios problemas sociais que afetam as comunidades que sobrevivem direta ou indiretamente do bioma da Mata Atlântica. Segundo o Censo Populacional 2010 do IBGE, mais de 61\% da população brasileira vivem neste bioma. Os danos são também na "diversidade cultural e na relação entre biodiversidade e sociodiversidade, e não somente na biodiversidade, como se afirma" (ADAMS, 2000). De acordo com Diegues e Arruda (2001), para as comunidades a mata representa o espaço de reprodução econômica, das relações sociais; o território pode ser visto também como locus das representações mentais e do imaginário mitológico das populações tradicionais.

Assim, o presente artigo insere-se na perspectiva de pensar a preservação do meio natural conjuntamente com o meio social, levando em consideração a presença das comunidades que vivem há muitas gerações nas áreas de proteção e dependem do uso sustentável dos recursos naturais e de práticas sociais e simbólicas. "Algumas dessas sociedades se reproduzem, explorando uma multiplicidade de hábitats: a floresta, os estuários, os mangues e as áreas já transformadas para fins agrícolas" (DIEGUES E ARRUDA, 2001).

O campo de pesquisa é o município de Baía Formosa (Figura1), localizado a 90 km de Natal, situado na Mesorregião Leste Potiguar, na Microrregião Litoral Sul do Estado do Rio Grande do Norte. Baía Formosa limita-se ao Leste e Norte com Oceano Atlântico; ao Oeste e Norte com o Município de Canguaretama; ao Sul faz fronteira com a Paraíba. O município localiza-se às margens de uma baía, possui uma área territorial de $245,661 \mathrm{Km}^{2}$, o equivalente a $0,47 \%$ da área estadual, sendo $26 \mathrm{~km}$ de praias e 2039,93 hectares compreendidos pela Mata Estrela. Segundo o IBGE (2013a), a população municipal está estimada em 9.048 habitantes e o Índice de Desenvolvimento Humano (IDH) corresponde a 0,609 (IBGE, 2010).

Figura 1 - Município de Baía Formosa/RN

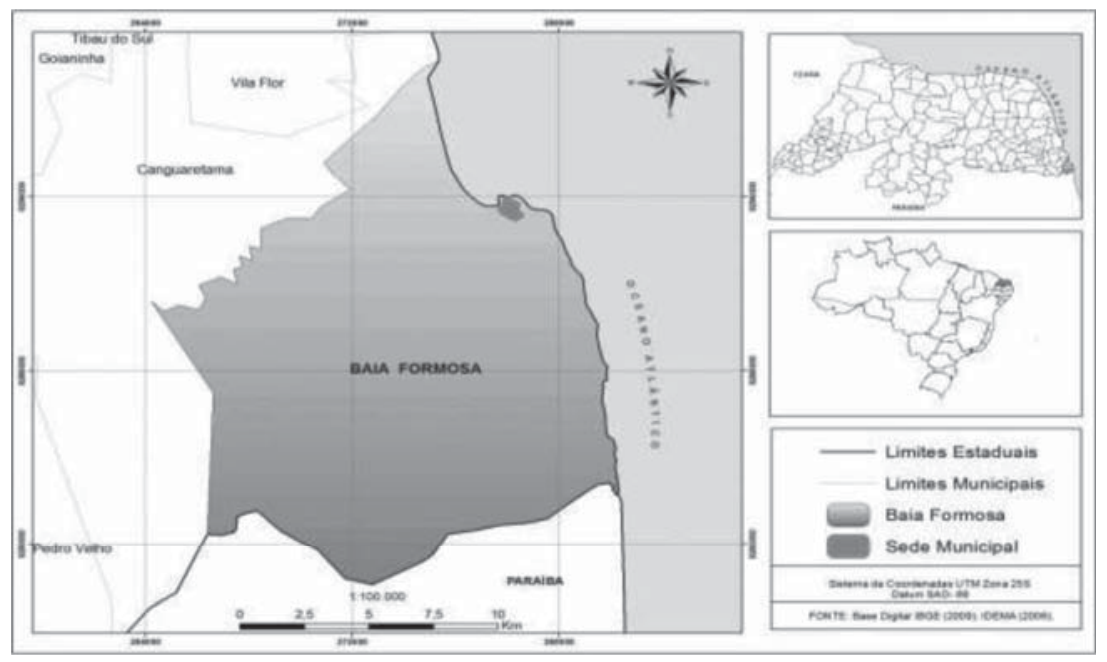

Fonte: Elaborado por Luzimar Pereira da Costa (2013).

Dentre as atividades econômicas do município podemos citar a pesca, o turismo, a carcinicultura e a agricultura, destacando-se a agroindústria através da monocultura de cana de açúcar e de uma usina de beneficiamento de açúcar e álcool combustível. 
A pesca comercial simples também contribui para a economia local. Segundo Silva (2011), a pesca da albacora (Thunnus albacares) e da lagosta vermelha (Panulirus argus) são as atividades pesqueiras mais conhecidas e rentáveis em Baía Formosa. Outras espécies são exploradas como o camarão e os peixes dourado, voador, cavala, arabaiana e sirigado, de acordo com o IDEMA (2004). Segundo Arnaldo da Silva Sena, Presidente da Colônia de Pescadores Z11 - João Tomé da Silva, fundada em 1949, na pesca são envolvidos cerca de mil pescadores, dentre os quais 832 estão cadastrados na colônia e 185 são mulheres.

O objetivo do presente artigo é identificar os principais impactos sociais na comunidade de pesca de Baía Formosa/RN, geradas a partir da instalação de uma usina sucroalcooleira e da criação de uma unidade de conservação, e analisa -los verificando a natureza destes, negativos ou/e positivos, diretos ou indiretos.

Para atender esses objetivos, a pesquisa fundamentou-se numa abordagem de natureza qualitativa. Realizou-se pesquisa bibliográfica, indispensável em qualquer trabalho de pesquisa. Na pesquisa de campo, por sua vez, foi empregada a observação direta que, em conjunto com os depoimentos dos interlocutores, permitiu analisar o relacionamento da comunidade com a mata e o modo como ela se organizou em função dos impactos sociais gerados pelas mudanças.

Para o estudo da mudança empregou-se a perspectiva diacrônica, utilizando-se do método da história oral. Para um melhor resultado do método escolhido foi importante empregar conjuntamente algumas técnicas e instrumentos adequados à captação de informações como a observação direta, entrevista, registros de imagens e gravações, com isso obteve-se e organizaram-se os dados úteis à pesquisa.

A pesquisa foi realizada com a comunidade de pescadores de Baía Formosa. Após os primeiros contatos com a comunidade e em virtude do seu grande universo, necessitou-se da escolha de um universo menor. Para isso, as informações iniciais para a seleção deste foram obtidas por meio de conversas informais com o presidente da colônia de pescadores Z-11, com os fundadores do sindicato dos trabalhadores rurais e com informantes locais. Partiu-se de uma amostra constituída por pescadores e moradores mais antigos e pescadores atuantes, dando ênfase àqueles reconhecidos e indicados pela comunidade como detentores de maior conhecimento sobre o passado e de experiências sobre a Mata.

Assim, foi empregada a técnica de entrevista com pescadores e moradores indicados como potenciais colaboradores da pesquisa. Nesta etapa, foram realizadas dezesseis entrevistas semiestruturadas, entre os meses de janeiro e junho de 2013. Esse número não foi definido a priori, foi estabelecido no decorrer do trabalho de campo, tendo em vista a quantidade e a qualidade das informações obtidas nos depoimentos iniciais. A cada entrevistado foi solicitado que indicasse outros potenciais colaboradores locais para a pesquisa. As entrevistas foram realizadas em diferentes espaços: na residência dos próprios entrevistados; espaços de convivência dos pescadores, como a sede da colônia, a praça dos pescadores e o porto de embarcações.

\section{ALGUNS ASPECTOS SOBRE A \\ 114 IMPLANTAÇÃO DA USINA E A UNIDADE DE CONSERVAÇÃO}

Para os estudos de impactos sociais é importante levar em conta as múltiplas escalas e dimensões temporais e espaciais, reconhecendo que esses mudam com o tempo (INSTITUTO INTERNACIONAL DE EDUCAÇÃO DO BRASIL, 2011). Uma das dificuldades em estudos a posteriori é a necessidade 
de saber como era a situação social anterior. Na medida em que é necessário considerar tanto o tempo de criação ou implantação dos eventos e o momento em que se encontram como também considerar a história dos grupos sociais afetados e a sua disposição espacial.

Outra dificuldade é descobrir como isolar apenas os efeitos das unidades de conservação. Essa dificuldade acontece porque os efeitos se exercem em contextos onde outros atores e outras forças são sentidos. Os efeitos das áreas protegidas acontecem em sinergia com os demais aspectos (BARRETTO FILHO, 2009). No contexto estudado ainda é mais difícil isolar os efeitos da unidade de conservação ou isolar os efeitos da usina, pois a Reserva Particular do Patrimônio Natural Mata Estrela é uma unidade de conservação de caráter privado, com área de propriedade da usina Vale Verde. O que nos faz analisar os impactos destes dois eventos de forma conjunta e não de forma isolada. Além de empreendimentos industriais e de áreas protegidas outras forças atuam impactando a comunidade de pescadores como o turismo, a carcinicultura, a especulação imobiliária e a inovação tecnológica na pesca. Mas para efeito deste estudo nos detivemos nos efeitos da usina e da unidade de conservação.

Segundo Brechin et al. (1991 apud INSTITUTO INTERNACIONAL DE EDUCAÇÃO DO BRASIL, 2011), impactos sociais geralmente se referem a consequências, antecipadas ou não, de eventos ou ações anteriores que "alteraram a habilidade de uma unidade social (individual ou coletiva) funcionar como no passado". Tais impactos podem ser negativos ou positivos, indo desde os físicos aos mais intangíveis, "dependendo do que foi alterado e de seus valores sociais, conforme a definição da unidade social afetada" (op. cit.). Em se tratando de áreas protegidas, Henyo Barretto define os impactos sociais como qualquer efeito ou consequência positiva ou negativa gerado pela criação, implementação ou gestão de áreas protegidas que modifique o modo de vida e o bem-estar econômico, social e/ou cultural dos grupos sociais afetados (2009).

Levando em consideração a dimensão temporal e história da comunidade afetada, recorremos à memória desta, buscando histórias que versam sobre a própria no passado para compreendermos como os pescadores (Figura 2) receberam as mudanças e a intervenção do empreendimento industrial e da criação de uma área de preservação ambiental.

Figura 2 - Pescadores de Baía Formosa/RN.

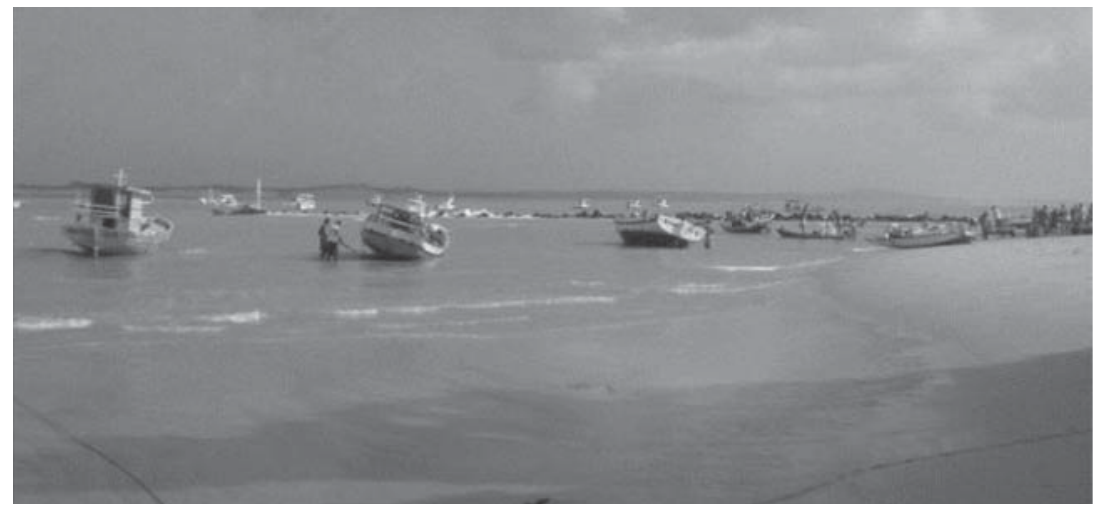

Foto: Julienne Govindin, 2013.

A partir das experiências vividas, os impactos sociais diretos foram identificados como: perda do acesso às áreas de plantio, restrição de acesso aos recursos naturais, geração de empregos, visibilidade ao município; desmatamento e preservação. 


\title{
PERDA DO ACESSO Às ÁREAS DE PLANTIO
}

A comunidade pesqueira de Baía Formosa pode ser classificada como camponesa dentro da perspectiva de Firth (1974):

"[...] de forma ampliada o sentido do termo camponês abarca pequenos produtores, tais como o pescador ou o artesão rural, que participam do mesmo tipo de organização econômica simples e de vida em comunidade. O pescador, pode de fato ser também um agricultor camponês durante parte do tempo."

Então, a chegada da usina impactou diretamente e negativamente a comunidade, pois ela perdeu acesso a terras utilizadas para o plantio de pequenos roçados, áreas que deram lugar para o plantio da cana de açúcar. Com isso os roçados foram pressionados para o entorno da mata. Posteriormente, com a criação da unidade de conservação, a comunidade foi cada vez mais pressionada a abandonar esta prática social. Ela não possui terras e mais de $80 \%$ das terras do município é de propriedade da usina, sendo grande parte empregada na monocultura da cana e outra parte compreende a unidade de conservação. Existem outros espaços não ocupados, mas a comunidade não tem permissão para usar estas terras. O trecho da entrevista a seguir, exemplifica esta dificuldade vivenciada pela comunidade.

\begin{abstract}
"Alcancei o Frederico, ele deixava a gente trabalhar, porque era o meio de vida daqui da maioria dos trabalhadores de roçado [...] Ai venderam para Dr. Antônio, ai ele foi terminou desmatando e foi fazendo a usina, e construiu a usina, eu não trabalhei não, trabalhei só uma semana mesmo graças a deus, trabalhei mais não. Não deixou mais não, só desmatava, pra eles né, pra botar cana, muita gente trabalhou mas só pra o dono da usina, inclusive [...] se você passar num rio que tem aí, o tal rio da estrela que tem uma poçeira aqui, desse lado aquilo ali foi onde a gente trabalhou, na vagem, o que a gente chama de paú, pra plantar banana, macaxeira, batata essas coisas toda, na época do verão, trabalhei muito mais meus pais ali, mas no tempo de Frederico, agora ele não deixa, o homem não deixa, os pau tá lá, mas ele não deixa ninguém trabalhar". (Entrevistado nº 3, 63 anos).
\end{abstract}

A perda do acesso a áreas de plantio impactou negativamente na comunidade, pois indiretamente isto contribuiu para o declínio da prática da agricultura, o que acarretou na perda de uma atividade que se configurava como um dos meios de reprodução, uma vez que as roças eram cultivadas de forma a suprir a necessidade de subsistência.

"A agricultura desempenhava a segunda atividade laboral, cujas famílias de pescadores dedicavam-se ao cultivo da terra, plantando e colhendo feijão, macaxeira, milho, batata, inhame. Essa atividade complementar garantia os meios necessários para uma dieta alimentar satisfatória à reprodução social.” (SILVA, 2012, p. 76).

Indiretamente também, a perda do acesso das áreas de plantio contribuiu para a perda do patrimônio cultural local, material e imaterial. No passado existiam duas casas de farinha no município, hoje não existe mais nenhuma, como foi relatado pelo interlocutor no fragmento abaixo:

"A casa de farinha daqui era naquele canto que fizeram essa fábrica de gelo, foi no tempo que formosa foi se endireitando, fizeram logo essa fábrica de gelo". (Entrevistado n 1, 97 anos).

Isto se deve à falta de incentivo para a agricultura (cultivo da mandioca) e consequentemente a produção da farinha. Ao se desativar as casas de 
farinha perde-se o patrimônio material e também o imaterial, como o conhecimento tradicional do fabrico da farinha.

\title{
RESTRIÇÃO DE ACESSO AOS RECURSOS NATURAIS
}

Outro patrimônio imaterial que vem declinando entre os membros da comunidade é o conhecimento tradicional da arte da carpintaria naval, fato este devido à restrição de acesso aos recursos naturais, sobretudo a madeira, que impacta negativamente. Com a criação da unidade de conservação, a área passou a ficar sob fiscalização ambiental e a comunidade não teve mais acesso às madeiras de forma livre, o que acarretou num desestímulo a construção naval e consequentemente no desinteresse pelo conhecimento tradicional do saber-fazer barco. Hoje na comunidade só existem cinco pessoas detentoras desse conhecimento, mas somente três ainda atuam na arte. A seguir relato do interlocutor acerca da restrição a madeira:

\begin{abstract}
"Escondido, porque o IBAMA até hoje proíbe, então depois que ficou propriedade privada não se teve mais a liberdade nem sequer de tirar um cipó na mata, se tirar é escondido né, é roubo pra eles, ele acha que é roubo [...] para gente mesmo que tinha liberdade não ficou muito bom, porque a gente não pode nem andar na mata, se andar os vigia estão em cima, se pegar um pedaço de pau para fazer um cabo de uma foice numa enxada os vigia proíbem, quer dizer, pra mim não ficou muito bom, mas pra quem rouba de noite, que é acostumado a tirar de noite [...] mas agora ficou uma propriedade privada, estamos num curral, um beco sem saída". (Entrevistado n ${ }^{\circ}$ 3, 63 anos).
\end{abstract}

O que ocorre também indiretamente a restrição ao acesso aos recursos naturais, como a madeira, é uma alteração na valorização que se atribui as tradições, conhecimentos, habilidades e atitudes ligadas a bens culturais. Isso também ocorre no conhecimento sobre as plantas e suas propriedades medicinais. A Mata Estrela é um bem cultural material da comunidade. Como afirma Diegues (1997), o chamado patrimônio natural a ser protegido é parte integrante do patrimônio cultural das populações tradicionais, pois é o lugar de reprodução econômica, social e simbólica. Segundo Ataídes (1996), a cultura material pode ser compreendida como qualquer elemento do meio físico culturalmente apropriado. Portanto, a Mata Estrela como o espaço que abriga as práticas sociais e simbólicas da comunidade é o bem cultural material no qual a cultura imaterial é reproduzida.

\section{GERAÇÃO DE EMPREGOS}

A geração de empregos é apontada como um impacto direto para a comunidade. A implantação da usina gerou empregos, o que pode ser analisado de forma positiva e negativa. A geração de emprego pela usina é apontada positivamente no relato:

"Ela empregou muita gente, esse povo que era desempregado ela empregou tudo, foi só o desmatamento que desmatou tudo pra plantar cana. O que ela trousse de bom foi que empregou quem não tinha trabalho, foi o que trouxe de bom pra aqui”. (Entrevistado $n^{\circ} 1,97$ anos).

Por outro lado, existem alterações na disponibilidade destes empregos no campo. A grande parcela dos trabalhadores é safrista, que chegam ao número 
de dois mil. Os safristas são aqueles que trabalham somente no período da safra (seis meses) para o período do corte da cana de açúcar, ficando desempregados no período da entressafra, período do plantio. Além disto, a usina já empregou muitos trabalhadores rurais no período da safra. Hoje, com a mecanização no campo, esse número caiu bastante, pois a usina vem adquirindo colheitadeiras que desempregam em torno de 120 trabalhadores por cada máquina.

Assim, a geração de emprego pode ser identificada como um impacto social direto positivo e negativo. Indireta e negativamente, a geração de empregos pela usina contribui para o abandono de práticas sociais próprias, como a pesca. Muitos pescadores vão trabalhar na usina no período da safra, acarretando na perda de direitos trabalhistas como pescadores, perdendo toda a contribuição dada ao longo dos anos. Isso acaba desestimulando e muitos não voltam para a atividade da pesca, acarretando o abandono desta prática social, desvalorizando o conhecimento e habilidades tradicionais.

Impactando positiva e negativamente, tem se a unidade de conservação também como geradora de empregos. Esta tem atraído turistas, gerando empregos através das pousadas e hotéis da região, como também com guias locais para passeios na mata. Mas, por outro lado, não é permitido a todos o trabalho como guia, como pode ser observado neste trecho de entrevista:

\begin{abstract}
"Só que ela é tombada pelo patrimônio da união e tem um pessoal ai que faz passeio de buggy, e eu e ele como somos nativos aqui, se eu pegar um buggy e queremos ir na lagoa não pode entrar. Quando ela é tombada pelo patrimônio da união já tá dizendo... união... eles tem um monopólio muito grande ai que eles estão usando. Se é tombada pelo patrimônio da união então eles não tem o direito de chegar... mesmo que cobre uma taxa de 15 reais para entrar na lagoa, a gente querendo pagar e não tem esse direito.'(Entrevistado n ${ }^{\circ} 3,63$ anos).
\end{abstract}

A tendência é que os grandes beneficiados socialmente pela reserva não seja a comunidade, mas os visitantes. Isso acarreta na reprodução de desigualdade social, como bem coloca Barretto (2009): "as unidades de Conservação desempenham uma função de interesse social e, é preciso perguntar para o público e para a sociedade qual a visão deles [...]." A importância de se discutir os impactos é para que essas áreas de fato se consolidem, mas que se consolidem com a dimensão de justiça social. Ao estudar os impactos sociais, é possível medir e aquilatar os custos e os benefícios da conservação. Se não caminha com justiça social, a unidade vira instrumento de reprodução e desigualdade.

\title{
VISIBILIDADE DO MUNICÍPIO
}

Outro impacto da usina e da criação da unidade de conservação na comunidade, expressado nos relatos, é a visibilidade do município. A comunidade percebe essa visibilidade como positiva, pois trouxe infraestrutura que outrora não existia como rodovias e transporte, o que atraiu o turismo e investimentos no setor. Observa-se isto através do relato a seguir:

"Deixou formosa aberta, vem gente de todo canto praqui [...] mudou muito, formosa mudou muito, formosa mudou de gente, formosa de tudo no mundo formosa mudou, que formosa não era assim, quando vinha esse povo de fora, era um praqui e outro pracolá, agora não, agora o que vem pra formosa, fica na formosa mesmo [...] hoje em dia formosa tá uma cidade, que tem buraco por todo canto, aqui não tinha rodagem, não tinha nada, o movimento daqui era costa de burro, costa de cavalo." (Entrevistado $n^{\circ} 1,97$ anos). 


\title{
DESMATAMENTO E PRESERVAÇÃO
}

Um impacto positivo da criação da unidade de conservação é a contribuição na preservação ambiental barrando o avanço da cana na região, apesar de seguir interesses próprios da usina que ganha em isenção tributária. Por outro lado, antes da criação da reserva, a usina desmatou grandes áreas de Mata Atlântica para o cultivo de cana, o que além de impactar negativamente o meio ambiente, também impactou negativamente a comunidade, pois a mata era uma fonte de subsistência, práticas sociais e simbólicas. A seguir trechos de entrevista no qual foi relatado práticas ofensivas ao meio ambiente:

\begin{abstract}
"Se não tivesse destruído seria melhor, porque toda seca que existe aqui em Baía formosa foi através do desmatamento da mata. Foi esse desmatamento que ela fez, tão tocando fogo, de vez em quando tão tocando fogo, isso é um grande prejuízo pra mata, pra natureza, que de primeiro se chamava floresta, tem muitas qualidades de nome que se chama, o prejuízo foi grande, porque tudo que dava no pé de pau de árvore, porque a árvore faz sombra, aquela sombra evita muita quentura e aquele estrume que cai as folhas, ali vai acumulando e qualquer chuvazinha a planta sobe e num canto que não tem nada como é que vai ser? Pra molhar, pra botar, pra crescer uma árvore, uma fruta, uma planta não vai demorar?" (Entrevistado n 3, 63 anos).
\end{abstract}

\begin{abstract}
“Aqui na época tinha uns passarinhos por nome nanbu, de toda qualidade, tinha tipo umas quatro espécies, muito, na época eles comiam uma sementizinha do capim, mas agora tão foliando as sementes com veneno, você bate a mata da estrela todinha e você não vê um, eles tão matando a semente que eles comiam com veneno, nessa usina pra lá, quando a gente ia na lagoa d'agua, voava dois ou três nambu em cima do outro, agora a gente anda, só tem algum calango porque não vai comer a semente, mas outra qualidade, até as sombras tão se acabando, por causo do veneno que tão botando". (Entrevistado n 3, 63 anos).
\end{abstract}

Os impactos sociais na comunidade de pescadores de Baía formosa/ RN provocados pela agroindústria canavieira, através da monocultura da cana de açúcar e da implantação de uma usina de beneficiamento de açúcar e álcool combustível, e pela criação de uma unidade de conservação, podem ser resumidos no quadro sinótico a seguir:

Figura 3 - Quadro sinótico dos impactos sociais na comunidade de pescadores de Baía Formosa/RN.

\begin{tabular}{|c|c|c|}
\hline \multicolumn{3}{|c|}{ IMPACTOS SOCIAIS } \\
\hline $\begin{array}{l}\text { POSITIVOS E/OU } \\
\text { NEGATIVOS }\end{array}$ & DIRETOS & INDIRETOS \\
\hline \multirow{2}{*}{ Negativo } & \multirow{2}{*}{$\begin{array}{l}\text { Perda do acesso } \\
\text { às áreas de plantio }\end{array}$} & $\begin{array}{l}\text { Declínio de práticas sociais - agricultura / perda de } \\
\text { um dos meios de reprodução social }\end{array}$ \\
\hline & & $\begin{array}{l}\text { Perda do patrimônio cultural local/ Perda do saber- } \\
\text { fazer do fabrico da farinha }\end{array}$ \\
\hline \multirow{2}{*}{ Negativo } & \multirow{2}{*}{$\begin{array}{l}\text { Restrição de } \\
\text { acesso aos recur- } \\
\text { sos naturais }\end{array}$} & $\begin{array}{l}\text { Alteração na valorização que se atribui ao conheci- } \\
\text { mento ligado a mata }\end{array}$ \\
\hline & & Perda do saber-fazer da arte da carpintaria naval \\
\hline \multirow{4}{*}{ Positivo e negativo } & \multirow{4}{*}{$\begin{array}{l}\text { Geração de } \\
\text { empregos }\end{array}$} & Empregos na safra da cana de açúcar \\
\hline & & Abandono de práticas sociais - pesca \\
\hline & & Empregos atraídos pelo ecoturismo na mata \\
\hline & & Restrição de acesso para se trabalhar como guia \\
\hline \multirow{2}{*}{ Positivo } & \multirow{2}{*}{$\begin{array}{l}\text { Visibilidade do } \\
\text { município }\end{array}$} & Trouxe infraestrutura \\
\hline & & Atraiu o turismo \\
\hline \multirow[b]{2}{*}{ Negativo } & \multirow[b]{2}{*}{ Desmatamento } & Alteração dos recursos naturais \\
\hline & & $\begin{array}{l}\text { Perda do significado mítico ou sagrado agregado à } \\
\text { área perdida }\end{array}$ \\
\hline Positivo & Preservação & Contribui barrando o avanço da cana \\
\hline
\end{tabular}

Fonte: Pesquisa de campo, 2013. 


\section{CONCLUSÃO}

Através dos dados resultantes da pesquisa constata-se que os impactos sociais decorrentes da implantação da usina Vale Verde e da criação da unidade de conservação Mata Estrela sobre a comunidade de pescadores de Baía Formosa/RN, podem ser caracterizados como: direto, indireto, positivos, negativos, positivos/negativos. Os impactos diretos foram identificados como: perda do acesso às áreas de plantio, restrição de acesso aos recursos naturais, geração de empregos, visibilidade ao município, desmatamento e preservação. Os impactos negativos dentre estes são: perda do acesso às áreas de plantio, restrição de acesso aos recursos naturais e o desmatamento. O impacto identificado como positivo e negativo é a geração de emprego. Os impactos positivos são visibilidade ao município e a preservação ambiental.

Os impactos indiretos na comunidade provenientes destes últimos são: Declínio da prática da agricultura; abandono da prática social da agricultura; perda de um dos meios de reprodução social; perda do patrimônio cultural local; perda do saber-fazer do fabrico da farinha; alteração na valorização que se atribui ao conhecimento ligado a mata; perda do saber-fazer da arte da carpintaria naval; empregos na safra da cana de açúcar; abandono de prática social da pesca; empregos atraídos pelo ecoturismo na mata; restrição de acesso para se trabalhar como guia; infraestrutura; atração do turismo; desmatamento; preservação ambiental.

As maiores implicações na comunidade foram a perda do acesso às áreas de plantio e a restrição de acesso aos recursos naturais. Isso se deve ao fato da usina possuir uma área de mais de $80 \%$ do território do município, incluindo a área que abriga a Mata Estrela que, além de ser reserva de proteção ambiental também é propriedade privada, no qual o proprietário pode fazer uso sustentável e a comunidade não. Esses eventos promoveram mudanças na relação da comunidade com a Mata Estrela que contribuíram para o esmaecimento das suas práticas sociais e simbólicas.

A perda do livre acesso as áreas de plantio ocasionou no declínio da prática da agricultura, a comunidade perdeu acesso a terras utilizadas para o plantio de pequenos roçados, áreas que deram lugar para o plantio da cana de açúcar. Com isso os roçados foram pressionados para o entorno da mata. Posteriormente, com a criação da unidade de conservação, a comunidade foi cada vez mais pressionada a abandonar esta prática social, o que ocasionou a perda de um dos meios de reprodução social da comunidade, já que ela é classificada como camponesa formada por pescadores-agricultores e que as roças eram cultivadas de forma a suprir a necessidade de subsistência. Também vem ocorrendo o abandono da prática predominante da comunidade, a pesca, em virtude da oferta de emprego na usina, apesar desta oferta ser temporária e cada vez menor em virtude da mecanização do setor canavieiro.

Devido à restrição de acesso aos recursos naturais, sobretudo a madeira, o conhecimento tradicional da arte da carpintaria naval vem declinando entre os membros da comunidade. Com a criação da unidade de conservação, a área passou a ficar sob fiscalização ambiental e a comunidade não teve mais acesso às madeiras de forma livre, o que acarretou num desestímulo à construção naval e consequentemente no desinteresse pelo conhecimento tradicional do saber-fazer barco. Ocorrendo assim uma alteração na valorização que se atribui as tradições, conhecimentos, habilidades e atitudes ligadas a bens culturais. $\mathrm{O}$ mesmo ocorre no conhecimento sobre as plantas e suas propriedades medicinais.

O desmatamento também contribuiu para essa alteração dos recursos naturais como também na perda do significado mítico ou sagrado agregado à 
área perdida. Antes da criação da reserva, a usina desmatou grandes áreas de Mata Atlântica para o cultivo de cana, o que além de impactar negativamente o meio ambiente, também impactou negativamente a comunidade, pois a mata é um espaço de práticas sociais e simbólicas. Verifica-se a necessidade de estudos de impactos sociais para avaliar os custos-benefícios da criação de unidades de conservação e evitar modelos de conservação preservacionistas baseados na conservação limitada às atividades de proteção do mundo natural. Como também são importantes para avaliar projetos desenvolvimentistas, como a agroindústria canavieira, contribuindo assim para a conservação da biodiversidade em conjunto com as comunidades locais.

\section{REFERÊNCIAS}

ADAMS, Cristina. As populações caiçaras e o mito do bom selvagem: a necessidade de uma nova abordagem interdisciplinar. Revista de antropologia, São Paulo, v. 43, n.1, pp. 145-182, 2000. Disponível em: $<$ http://www.scielo.br/scielo.php?script=sci_arttext\&pi$\mathrm{d}=$ S0034-77012000000100005\&lng=en\&nrm=iso $>$. Acesso em: $07 \mathrm{abr}$. 2012.

ANDRADE, Manuel Correia de. Modernização e pobreza: a expansão da agroindústria canavieira e seu impacto ecológico e social. São Paulo: Ed. UNESP, 1994.

ATAIIDES, Heloísa Capel de. O resgate da cultura intangível na cultura material. In: Caldarelli, S. (Org.). Atas do Simpósio sobre Política nacional do Meio Ambiente e patrimônio Cultural. Instituto Goiano de Pré-História e Antropologia et al. Goiânia, 1997.

BARRETTO FILHO, Henyo Trindade. Impactos sociais nas áreas protegidas. WWF-Brasil, Brasília, 01 dez. 2009. Disponível em: <http://www.wwf. org.br/?23140/Entrevista-Henyo-Barreto-fala-sobre-impactos-sociais-nas-areas-protegidas $>$. Acesso em: 05 maio 2013.

BRASIL. Decreto $n^{0} 5.746$, de 5 de abril de 2006. Casa civil, Poder executivo, Brasília, DF, de 5 de abril de 2006. Disponível em: <http://www. planalto.gov.br/ccivil_03/_Ato2004-2006/2006/Decreto/D5746.htm>. Acesso em: 15 maio 2013.

DIEGUES, Antonio Carlos (Org.). Povos e águas: Inventário de áreas úmidas. São Paulo, NUPAUB/USP, 2ed, 2002.

. Reserva da biosfera da Mata Atlântica: Plano de Ação. V. 1: Referências Básicas. Consórcio Mata Atlântica, UNICAMP, junho/1992.

. O Patrimônio Natural e o Cultural: Por uma visão convergente. In: Caldarelli, S. (Org). Atas do simpósio sobre política nacional do meio ambiente e patrimônio cultural. Instituto Goiano de Pré-História e Antropologia et al, Goiânia, 1997.

. Etnoconservação da natureza: enfoques alternativos. In: Etnoconservação: novos rumos para a proteção da natureza nos trópicos. São Paulo: Ed. HUCITEC, 2000.

DIEGUES, Antonio Carlos; ARRUDA, Rinaldo S. V. (Orgs.). Saberes tradicionais e biodiversidade no Brasil. Brasília: Ministério do Meio Ambiente; São Paulo: USP, 2001.

FIRTH, Raymond. Mudança Social em comunidades camponesas. In: Elementos de Organização Social. Rio de Janeiro: Zahar, 1974. 
GRUPO FARIAS. Apresentação institucional: setor sucroenergético. 2013. Disponível em: $<$ http://www.grupofarias.com.br/index_2.html $>$. Acesso em: 20 nov. 2013.

INSTITUTO BRASILEIRO DE GEOGRAFIA E ESTATISTICA. Censo demográfico 2010. Disponível em: <http:// www.ibge.gov.br/cidadesat/ link. php?codmun=240140 . Acesso em: 17 fev. 2013.

. Estimativas da população residente com data de referência

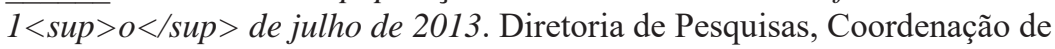
População e Indicadores Sociais: IBGE 2013. Disponível em: <http://www. cidades.ibge.gov.br/xtras/perfil.php?lang $=\&$ codmun $=240140 \&$ search $=$ riogrande-do-norte|baia-formosa > Acesso em: 20 jan. 2014.

. Produção agrícola municipal 2012. Rio de Janeiro: IBGE 2013.

Disponível em: <http://www.cidades.ibge.gov.br/xtras/perfil.php?lang=\&codmun $=240140 \&$ search $=$ rio-grande-do-norte|baia-formosa $>$. Acesso em: 20 jan. 2014.

\section{INSTITUTO DE DESENVOLVIMENTO SUSTENTÁVEL E MEIO} AMBIENTE DO RIO GRANDE DO NORTE. Caracterização da pesca artesanal do estado do Rio Grande do Norte. Natal, 2004.

INSTITUTO INTERNACIONAL DE EDUCAÇÃO DO BRASIL. Avaliação de impactos sociais de áreas protegidas no Brasil: caminhos e desafios. Brasil, 2011.

INSTITUTO NACIONAL DE PESQUISAS ESPACIAIS e FUNDAÇÃO SOS MATA ATLÂNTICA. Atlas dos remanescentes florestais da Mata Atlântica - período 2011-2012: Relatório Técnico. São Paulo, 2013. Disponível em: <http://mapas.sosma.org.br/dados/>. Acesso em: 14 mai. 2013.

SCHIAVETTI, A; MAGRO, T.C.; SANTOS, M.S. Implementação das Unidades de Conservação do corredor central da Mata Atlântica no Estado da Bahia: Desafios e limites. Revista árvore, Viçosa-MG, v.36, n.4, p.611-623, 2012. Disponível em: <http://www.scielo.br/scielo.php?pi$\mathrm{d}=\mathrm{S} 0100-67622012000400004 \&$ script $=$ sci_arttext $>$. Acesso em: $22 \mathrm{mar}$ 2013.

SILVA, Adriana Elias. A Usina Vale Verde: A expansão dos capitais, o processo produtivo e sua integração socioeconômica no município de Baía Formosa/ RN. Monografia, Serviço Social, UFRN, 2012.

SILVA, Rubens Elias da. Guiados por mares e peixes: Memória social, inovação tecnológica e o processo de fragmentação na pequena pesca comercial simples em duas comunidades costeiras no Rio Grande do Norte. Tese/UFPB. João Pessoa, 2011. 